\title{
Advanced Specialty Pediatric Hospitals Position Statement August 2, 2012: Nitric Oxide Use for Pulmonary Hypertension in Preterm Neonates
}

Don Null, MD

This statement was originally written to the United States Food and Drug Association in 2012. Despite increasing evidence to support the effectiveness of inhaled Nitric Oxide in premature infants with physiologic pulmonary hypertension, the use of iNO in this population is not routine. Dr. Null submitted this statement on behalf of the original authors of the document, which is included in this submission, along with the letter written by $F$. Sessions Cole.

The following national network of board-certified Neonatologists and Pediatric Intensivists recognize the administration and charge for inhaled Nitric Oxide (iNO) in neonates less than 34 weeks gestation in the treatment of pulmonary hypertension as both medically appropriate and a community standard of care practiced by Advanced Specialty Pediatric Hospitals across the United States. Insurance company refusal to reimburse for this standard of care reflects inappropriate application of labeling by the Food and Drug Administration (FDA).

\section{"The following national network of board-certified Neonatologists and Pediatric Intensivists recognize the administration and charge for inhaled Nitric Oxide (iNO) in neonates less than 34 weeks gestation in the treatment of pulmonary hypertension as both medically appropriate and a community standard of care practiced by Advanced Specialty Pediatric Hospitals across the United States."}

Our national network supports the FDA's labeling of inhaled Nitric Oxide as inappropriate for the treatment of lung disease in infants less than 34 weeks gestational age for bronchopulmonary lung disease. However, we do support the use of Nitric Oxide in neonates less than 34 weeks gestational age with severe respiratory failure with evidence of pulmonary hypertension that have shown no improvement with ventilation strategies. Additionally, we support the use of Nitric Oxide in patients who are older ex-premature infants with severe Chronic Lung Disease (CLD) that developed secondary pulmonary hypertension. Pulmonary hypertension is a condition in which pulmonary artery blood pressure is abnormally high; this can dramatically increase the possibility of requiring heart and lung support via extracorporeal membrane oxygenation (ECMO). Our physician experts and leaders practice under extreme real-life circumstances. They are familiar with this deteriorating condition as they follow advances in technological science, research, clinical practice, and community standards of care when making clinical judgments to treat the patient. Medicine is based upon many diverse sources, and for neonates, these sources involve very few large clinical trials. The large clinical trial used as the basis for the FDA's labeling had gestational limitations inherent in their sampling, which included patients that were 34 weeks gestation and greater. This gestation age limitation was related to criteria for ECMO since one of the major outcome variables being tested was a reduction in the need for ECMO. But the most important outcome was the recognition that iNO is an effective therapy for pulmonary hypertension, and this is the basis for treating any infant with the diagnosis of pulmonary hypertension who is not responding to routine therapy regardless of their gestational or postnatal age. Community standards of care in medical practice evolve due to the extensive period required to methodically study patient groups and obtain regulatory approval.

\section{"But the most important outcome was the recognition that iNO is an effective therapy for pulmonary hypertension, and this is the basis for treating any infant with the diagnosis of pulmonary hypertension who is not responding to routine therapy regardless of their gestational or postnatal age."}

Per a review in the Cochrane Collaborative, the U.S and international use of pulse oximetry as "a tool that guides the anesthesiologists in the daily management of patients, in teaching situations, in emergencies and especially in caring for children" is in the absence of scientific evidence supporting such perioperative monitoring. (1) Despite requiring further scientific study, community standards of care are widely accepted and regarded as an integral part of making important medical decisions.

Based upon the National Institutes of Health (NIH) Consensus and utilizing state-of-the-science statements, this practice of utilizing Nitric Oxide on premature newborns is deemed appropriate based upon clinicians' judgment. (2) In rare clinical situations, Nitric Oxide "may have benefit in 
infants <34 weeks' gestation." (2) The available evidence is equivocal and, therefore, does not suggest Nitric Oxide "either increases or decreases the risk of several shortterm complications of prematurity." (2) In other words, the available early evidence involved a small number of very high-risk patients at high risk for mortality who are extremely difficult to study. This is why independent panelists and public representatives participating in the NIH Consensus conclude that the use of Nitric Oxide in premature infants "should be left to clinical discretion." (2)

\section{"In association with the Child Health Corporation of America (CHCA), a consortium of free-standing pediatric hospitals, it is our position that the use of nitric oxide in infants of less than}

\section{4 weeks gestation with pulmonary} hypertension is a community standard of practice."

Per the Agency for Healthcare Research and Quality under the U.S. Department of Health and Human Services, "we should not abandon the possibility that iNO may someday become a component of a treatment strategy for some preterm infants receiving respiratory support. Several factors contribute to our recommendation to continue the study of iNO: 1) our finding of a small but statistically significant difference in death or BPD at 36 weeks PMA, the common primary outcome variable of $73 \%$ of RCT conducted to-date; 2) the statistically significant finding of a diminished need for chronic pulmonary medication at one year corrected age, suggesting less severe lung disease in those treated with iNO, and 3) no studies have been powered to detect meaningful differences in infant functional outcome or quality of life with iNO treatment compared to standard therapy." (3) Future studies into premature birth in the U.S. and internationally will assist in providing a clearer strategy for the FDA to issuelabeling changes.

In association with the Child Health Corporation of America (CHCA), a consortium of free-standing pediatric hospitals, it is our position that the use of nitric oxide in infants of less than 34 weeks gestation with pulmonary hypertension is a community standard of practice. We are a community of recognized leaders in providing the highest quality and excellence in pediatric medicine. We are committed to providing safety, quality performance, education, research, and child health advocacy co11joined with forward-thinking, ethics, and integrity in the vision of transforming healthcare.

In summary, Nitric Oxide use in preterm neonates with pulmonary hypertension is in accordance with $2011 \mathrm{NIH}$ guidelines and not addressed in the current FDA labeling due to the lack of clinical studies. Furthermore, the use of Nitric Oxide in preterm neonates is a standard of practice at free-standing pediatric hospitals across the country. Based on this community standard of practice, we use Nitric Oxide in a medically appropriate manner.

\section{References:}

1. Pedersen, T., et al., Pulse oximetry for perioperative monitoring. Cochrane Database of Systematic Reviews 2009, Issue 4. Art. No.:CD002013. DOI: 10.1002/14651858.CD002013.pub2

2. "NIH Consensus Development Conference Statement: Inhaled Nitric-Oxide Therapy for Premature Infants." Journal of the American Academy of Pediatrics 127.2 (2011): 363- 69. Web. September 28, 2011.

3. Allen MC., et al., Inhaled Nitic Oxide in Preterm Infants, Evidence Report/ Technology Assessment No. 195, (Prepared by Johns Hopkins University Evidence-based Practice Center under Contract No. 290-2007-10061-I). AHRQ Publication No. 11-E00I. Rockville, MD: Agency for Healthcare Research and Quality. October 2010.

\section{NT}

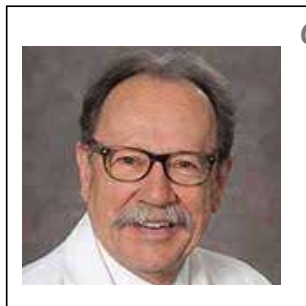

Corresponding Author

Donald Null, MD

Professor of Pediatrics

Division of Neonatology

Department of Pediatrics

University of California, Davis

'Donald M Null'< dnull@ucdavis.edu>

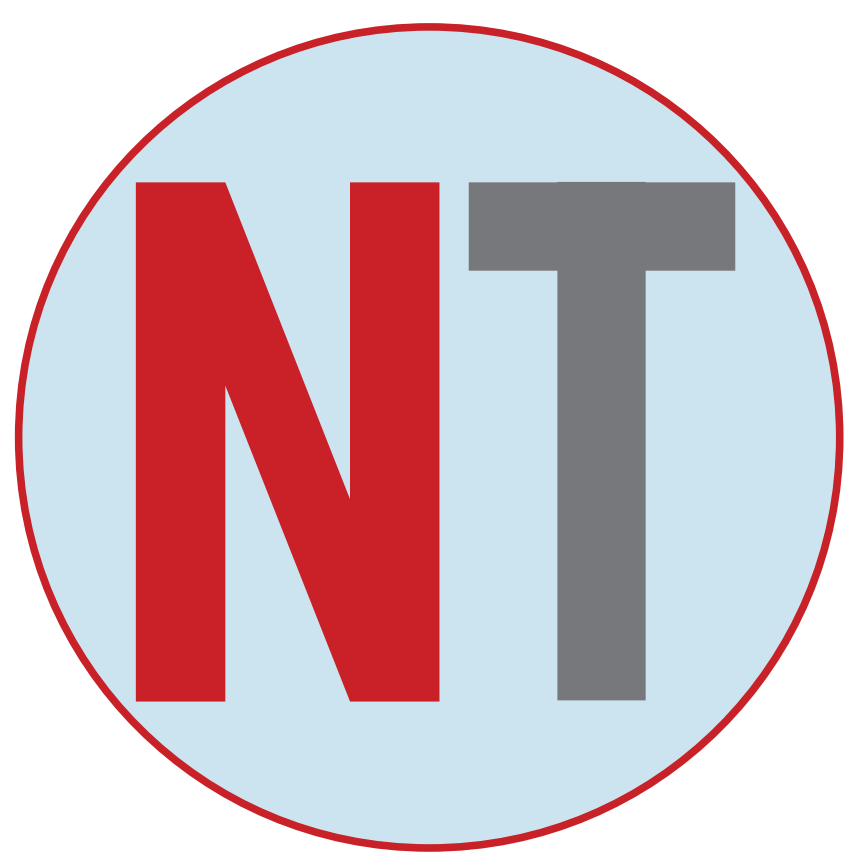




\section{WashingtonUniversity Physicians}

Washington University School of Medicine in St.Louis

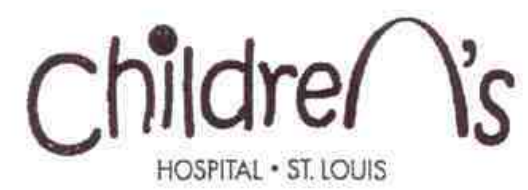

Department of Pediatrics

Division of Newborn Medicine

3 August 2012

Mary Daymont, R.N., M.S.N., C.C.M.

Children's National Medical Center

Executive Director of Clinical Resource Management

111 Michigan Avenue NW

Washington, DC 20010

Dear Ms. Daymont:

As the Chairman of the Consensus Conference concerning use of inhaled nitric oxide in premature infants sponsored by the National Institutes of Health (Pediatr 2011;127:363), I oversaw and participated in a 2 year process of systematic data collection, review, and discussion. The conclusions of the conference included a specific acknowiedgement of potential benefit of inhaled nitric oxide for clinical situations that included pulmonary hypertension or hypoplasia in premature infants (conclusion 2). This conclusion and the data upon which it is based were discussed in depth by the Committee. The data indicate that inhaled nitric oxide may be life saving in some populations of premature infants (e.g., infants with pulmonary hypertension), establish its use as a nationally recognized standard of practice, and demonstrate that inhaled nitric oxide should not be denied to any infant based on insurance coverage. Failure of insurance companies to cover the cost of use of inhaled nitric oxide in these clinical situations is inconsistent with current evidence, national practice standards, and with the Consensus Statement conclusions.

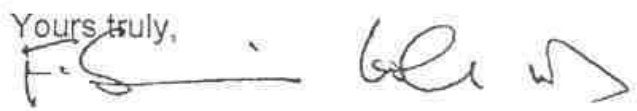

F. Sessions Cole, M.D.

Chairman, NIH Consensus Conference: Inhaled Nitric Oxide Therapy for Premature Infants

Park J. White, M.D., Professor of Pediatrics

Assistant Vice Chancellor for Children's Health

Vice Chairman, Department of Pediatrics

Director, Division of Newborn Medicine

Chief Medical Officer, St. Louis Children's Hospital

Cc: Claudia Alleyne, M.D.

John D. E. Barks, M.D.

Robert J. Boyle, M.D.

John L. Carroll, M.D.

Deborah Dokken, M.P.A.

William H. Edwards, M.D.

Michael Georgieff, M.D.

Katherine Gregory, Ph.D., R.N.

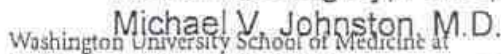

Washington University Medical Center, Campus Box 8116,

One Children's Place, St. J.ouis, Missouri 63110.

(314) 454-6148, Fax (314) 454-4633

peds.wustledu/div/newborn/

St. Louis Children's I I tuspital is a member of Bd HealthCare' 
Michael Kramer, M.D.

Christine Mitchell, M.S., R.N., M.T.S.

Josef Neu, M.D.

DeWayne M. Pursley, M.D., M.P.H.

Walter Robinson, M.D., M.P.H.

David Rowitch, M.D., Ph.D. 


\section{Advanced Specialty Pediatric Hospitals Position Statement August 2, 2012}

\section{Nitric Oxide Use for Pulmonary Hypertension in Pre-Term Neonates}

The following national network of board certified Neonatologists and Pediatric Intensivists recognize the administration and charge for inhaled Nitric Oxide (iNO) in neonates less than 34 weeks gestation in treatment of pulmonary hypertension as both medically appropriate and a community standard of care practiced by Advanced Specialty Pediatric Hospitals across the United States. Insurance company refusal to reimburse for this standard of care reflects inappropriate application of labeling by the Food and Drug Administration (FDA).

Our national network supports the FDA's labeling of inhaled Nitric Oxide as inappropriate for the treatment of lung disease in infants less than 34 weeks gestational age for bronchopulmonary lung disease. However, we do support the use of Nitric Oxide in neonates less than 34 weeks gestational age with severe respiratory failure with evidence of pulmonary hypertension that have shown no improvement with ventilation strategies. Additionally, we support the use of Nitric Oxide in patients who are older ex-premature infants with severe Chronic Lung Disease (CLD) that developed secondary pulmonary hypertension. Pulmonary hypertension is a condition in which pulmonary artery blood pressure is abnormally high; this can dramatically increase the possibility of requiring heart and lung support via extracorporeal membrane oxygenation (ECMO). Our physician experts and leaders practice under extreme real-life circumstance. They are familiar with this deteriorating condition as they follow advances in technological science, research, clinical practice and community standards of care when making clinical judgments to treat the patient. Medicine is based upon many diverse sources and for neonates these sources involve very few large clinical trials. The large clinical trial used as the basis for the FDA's labeling had gestational limitations inherent in their sampling which included patients that were 34 weeks gestation and greater. This gestation age limitation was related to criteria for ECMO since one of the major outcome variables being tested was reduction in the need for ECMO. But the most important outcome was the recognition that iNO is an effective therapy for pulmonary hypertension and this is the basis for treating any infant with the diagnosis of pulmonary hypertension who is not responding to routine therapy regardless of their gestational or postnatal age. Community standards of care in medical practice evolve due to the extensive period required to methodically study patient groups and obtain regulatory approval. Per a review in the Cochrane Collaborative, the U.S and international use of pulse oximetery as "a tool that guides the anesthesiologists in the daily management of patients, in teaching situations, in emergencies, and especially in caring for children" is in absence of scientific evidence supporting such perioperative monitoring [1]. Despite requiring further scientific study, community standards of care are widely accepted and regarded as an integral part of making important medical decisions.

Based upon the National Institutes of Health (NIH) Consensus and utilizing state-of-the-science statements, this practice of utilizing Nitric Oxide on premature newborns is deemed appropriate based upon clinicians' judgment [2]. In rare clinical situations, Nitric Oxide "may have benefit in infants $<34$ weeks' gestation" [2]. The available evidence is equivocal and therefore, does not suggest Nitric Oxide "either increases or decreases the risk of several short-term complications 
of prematurity" [2]. In other words, the available early evidence involved a small number of very high risk patients at high risk for mortality who are extremely difficult to study. This is why independent panelists and public representatives participating in the NIH Consensus conclude that use of Nitric Oxide in premature infants "should be left to clinical discretion" [2].

Per the Agency for Healthcare Research and Quality under the U.S. Department of health and Human Services, "we should not abandon the possibility that iNO may someday become a component of a treatment strategy for some preterm infants receiving respiratory support. Several factors contribute to our recommendation to continue the study of iNO: 1) our finding of a small but statistically significant difference in death or BPD at 36 weeks PMA, the common primary outcome variable of $73 \%$ of RCT conducted to-date; 2 ) the statistically significant finding of a diminished need for chronic pulmonary medication at one year corrected age, suggesting less severe lung disease in those treated with iNO, and 3) no studies have been powered to detect meaningful differences in infant functional outcome or quality of life with iNO treatment compared to standard therapy" [3]. Future studies into premature birth in the U.S. and internationally will assist in providing clearer strategy for the FDA to issue labeling changes.

In association with the Child Health Corporation of America (CHCA), a consortium of free standing pediatric hospitals, it is our position that the use of nitric oxide in infants of less than 34 weeks gestation with pulmonary hypertension is a community standard of practice. We are a community of recognized leaders in providing the highest quality and excellence in pediatric medicine. We are committed to providing safety, quality performance, education, research and child health advocacy conjoined with forward-thinking, ethics and integrity in the vision of transforming healthcare.

In summary, Nitric Oxide use in preterm neonates with pulmonary hypertension is in accordance with 2011 NIH guidelines and not addressed in the current FDA labeling due to the lack of clinical studies. Furthermore the use of Nitric Oxide in preterm neonates is a standard of practice at free standing pediatric hospitals across the country. Based on this community standard of practice, we use Nitric Oxide in a medically appropriate manner.

1. Pedersen, T., et al., Pulse oximetry for perioperative monitoring. Cochrane Database of Systematic Reviews 2009, Issue 4. Art. No.:CD002013. DOI: 10.1002/14651858.CD002013.pub2

2. "NIH Consensus Development Conference Statement: Inhaled Nitric-Oxide Therapy for Premature Infants." Journal of the American Academy of Pediatrics 127.2 (2011): 363 69. Web. 28 Sept. 2011.

3. Allen MC., et al., Inhaled Nitric Oxide in Preterm Infants, Evidence Report/ Technology Assessment No. 195. (Prepared by Johns Hopkins University Evidence-based Practice Center under Contract No. 290-2007-10061-1). AHRQ Publication No. 11-E001. Rockville, MD: Agency for Healthcare Research and Quality. October 2010. 
Dr Jacquelyn R Evans

EVANS@email.chop.edu

The Children's Hospital of Philadelphia

3400 Civic Center Blvd

Philadelphia, PA 19104

Dr. Rashmin Savani

Rashmin.Savani@UTSouthwestern.edu

Univ of Texas Southwestern Medical Center

5323 Harry Hines Boulevard

Dallas, Texas, 75390

Dr. Beverly S. Brozanski

Beverly.Brozanski@chp.edu

Children's Hospital of Pittsburgh

4401 Penn Avenue

Pittsburgh, PA 15223

Dr. Philippe S. Friedlich

pfriedlich@chla.usc.edu

Children's Hospital Los Angeles

4650 Sunset Blvd

Los Angeles, CA 90027

Dr. Kris Reber

Kris.Reber@nationwidechildrens.org

Nationwide Children's Hospital

700 Children's Drive

Columbus, Ohio 43205

Dr. Amit Mathur

mathur_a@kids.wustl.edu

Dr. Tasnim Najaf

najaf t@@kids.wustl.edu

St. Louis Children's Hospital

One Children's Place

St. Louis, MO • 63110

Dr. David J. Durand

DDurand@mail.cho.org

Children's Hospital Oakland

747 52nd St.

Oakland, CA 94609
Dr. Anne Hansen

Anne.Hansen@childrens.harvard.edu

Children's Hospital Boston

300 Longwood Avenue

Boston, MA 02115

Dr. Ramasubbareddy Dhanireddy

rdhanire@uthsc.edu

Le Bonheur Children's Hospital

50 N. Dunlap Street

Memphis, Tennessee 38103

Dr. Roberto Sosa

Rajan.Wadhawan@,allkids.org

All Children's Hospital

5016 th Avenue South

St. Petersburg, FL 33701

Dr. Eugenia Pallotto

ekpallotto@cmh.edu

The Children's Mercy Hospital

2401 Gillham Road

Kansas City, MO 64108

Dr. Karna Murthy

k-murthy@northwestern.edu

Children's Memorial Hospital

2300 Children's Plaza

Chicago, Illinois 60614

Dr. Donald Null

Donald.Null@hsc.utah.edu

Primary Children's Medical Center

100 Mario Capecchi Dr

Salt Lake City, UT 84113

Dr. Gail Knight

gknight@rchsd.org

Rady Children's Hospital

3020 Children's Way

San Diego, CA 92123 
Dr. Michael R. Uhing

muhing@mow.edu

Children's Hospital of Wisconsin

9000 W. Wisconsin Ave

Milwaukee, WI 53226

Dr. John Berger

jberger@childrensnational.org

Dr. Billie Short

bshort@childrensnational.org

Children's National Hospital

111 Michigan Ave NW

Washington, DC 20010

Dr. William Walsh

William.Walsh@Vanderbilt.Edu

Monroe Carell Jr. Children's Hospital

2200 Children's Way

Nashville, TN 37232

Dr. Carl H. Gumbiner

cgumbiner@ChildrensOmaha.org

Dr. Luke Noronha

lnoronha@ChildrensOmaha.org

Children's Hospital \& Medical Center

8200 Dodge Street

Omaha, NE 68114

Dr. Stephen Welty

sewelty@texaschildrenshospital.org

Texas Children's Hospital

Dr. Steven Abman

Steven.Abman@ucdenver.edu

Children's Hospital Colorado

13123 East 16th Avenue

Aurora, CO 80045

Dr. Satyan Lakshminrusimha

slakshmi@buffalo.edu

Women and Children's Hospital of Buffalo

219 Bryant Street

Buffalo, NY 14222
Dr. Francine Dykes

fdykes@emory.edu

Children's Healthcare of Atlanta

1405 Clifton Road NE

Atlanta, GA 30322

Dr. Linda D. Wallen

wallenld@uw.edu

Dr. J. Craig Jackson

craig.jackson@seattlechildrens.org

Seattle Children's Hospital

4500 Sand Point Way NE

Seattle, Washington 98105

Dr. Jefry L. Biehler

Jefry.Biehler@mch.com

Miami Children's Hospital

3100 Southwest 62nd Avenue

Miami, FL 33155 